\title{
Fetal arrhythmia caused by excessive intake of caffeine by pregnant women
}

\author{
S Guid Oei, Robert P L Vosters, \\ Nanette L J van der Hagen
}

Department of Obstetrics and Gynaecology, Rijnstate Hospital DH, 6814 HK Arnhem, The Netherlands S Guid Oei, MD, registrar Robert P L Vosters, MD, consultant

Nanette L J van der Hagen, $\mathrm{MD}$, research fellow

Correspondence to: Dr Oei.

Br.Med f 1989;298:568

\section{Department of Infectious \\ Disease M, Rigshospitalet, DK 2200 Copenhagen, Denmark \\ N H Riewerts Eriksen, $M D$, registrar \\ P Skinhøj, MD, chief \\ physician}

\section{Department of Clinical}

Microbiology, Statens

Seruminstitut,

Rigshospitalet, DK 2200

Copenhagen

F Espersen, MD, registrar

$\mathrm{N}$ Høiby, MD, chief physician

Medical Department A,

Rigshospitalet, DK 2100

Copenhagen

L Laursen, MD, registrar

Neisseria Department, Statens Seruminstitut, DK 2300 Copenhagen

I Lind, MD, chief physician

Correspondence to: $\mathrm{Dr}$ Eriksen.

Br.Med f 1989;298:568-9
We report three cases of fetal arrhythmia resulting from excessive intake of caffeine by the mother during pregnancy.

\section{Case reports}

Case 1-The patient was a 26 year old woman (gravida 5, para 2). From 34 to 36 weeks of gestation preterm labour was successfully suppressed with fenoterol. Ten days later, when labour began spontaneously, the fetal heart rhythm was totally irregular; it had previously been regular. She gave birth to a boy who weighed $3100 \mathrm{~g}$; his Apgar score at 5 minutes was 8. Electrocardiography showed frequent blocked extrasystoles resulting in bradycardia. After three days the extrasystoles stopped without medical intervention. Chest radiography, echocardiography, and laboratory tests yielded normal results. The only remarkable finding was that the woman had drunk 10 cups of coffee $(1500 \mathrm{ml})$ during the last hours before delivery. The baby's urine contained caffeine.

Case 2-A 23 year old woman was admitted to this hospital at 40 weeks' gestation to deliver her first baby. The fetal heart beat was irregular, although three weeks previously it had been regular as measured by cardiotocography. Echocardiography of the fetal heart did not show any abnormalities. The woman told us that she had drunk 1.5 litres of cola a day during the past two weeks because of the hot weather. She delivered a girl who weighed $2680 \mathrm{~g}$; the Apgar score at 5 minutes was 9. During and after delivery the fetal heart beat remained irregular. Postpartum electrocardiography showed frequent supraventricular extrasystoles. Laboratory tests yielded normal results. Over three days the arrhythmia gradually resolved. The baby's urine was not tested for caffeine.
Case 3-A 22 year old woman (gravida 1) was admitted to this hospital at 23 weeks' gestation because of fetal arrhythmia. Echocardiography of the fetal heart did not show any structural abnormalities; the heart beat was totally irregular. Results of laboratory tests were normal. The woman told us that she drank more than 1.5 litres of cola, two cups of coffee, and one cup of cocoa a day. She was told not to drink anything that contained caffeine. One week later the arrhythmias had stopped, and her pregnancy continued without problems.

\section{Comment}

Caffeine is a major pharmacological component of several popular beverages including coffee, tea, colas, and chocolate. Excessive intake of caffeine can cause tachycardia, extrasystoles, and arrhythmia.' Fetal arrhythmia, however, as a result of caffeine abuse by the mother has not been described before. Positive chronotropic and inotropic effects on fetal hearts, which depended on the caffeine concentration, have been shown in vitro..$^{2-4}$ As caffeine can readily cross the placenta and enter the fetal circulation it can probably also have adverse effects on the fetal heart in vivo.

Peak blood caffeine concentrations occur within 30 minutes after a subject drinks a cup of coffee, and caffeine has a metabolic half life of $2 \cdot 5-4 \cdot 5$ hours. In babies, however, the enzyme or enzymes necessary to metabolise caffeine are absent until several days after birth. ${ }^{5}$ Therefore, disturbances in the baby's heart rate caused by an excessive intake of caffeine by the mother should stop several days after birth.

These three cases show the importance of considering caffeine abuse by the pregnant woman if fetal arrhythmia of unknown origin occurs.

1 Ritchie JAI. The xanthines In: Goodman LS, Gilman A, eds. The pharmacological hasis of therapeutics. 3rd ed. New York: Macmillan, 1965:354.

2 Resch BA, Papp JG. Effects of caffeine on the fetal heart. Am 7 Obstel Gynecol 1983;146:231-2.

3 Resch BA, Papp JG, Gyongyosi J, Szell SJ. Die Wirkung des Koffeins auf die fetale Herzfrequenz und die Koffeinkonsum-Gewohnheiten der die fetale Herzfrequenz und die Koffeinkon

4 Resch BA, Papp JG, Gyongyosi J. Die Wirkung des Koffeins auf die Kontraktilität des fetalen Herzmuskels. Zentralbl Gynakol 1987;109:945-51. 5 Weathersby PS, Lodge JR. Caffeine: its direct and indirect influence on reproduction. I Reprod Med 1977;19:55-63.

(Accepted 25 November 1988 )

\section{Nosocomial outbreak of group C meningococcal disease}

\section{N H Riewerts Eriksen, F Espersen, L Laursen, P Skinhøj, N Høiby, I Lind}

We report three cases of group C:2a meningococcal disease occurring within a month in the same hospital department. A carrier study among patients and staff showed that the infections were due to the spread of the strain inside the hospital.

\section{Patients, methods, and results}

On day 1 a nasopharyngeal swab was taken and a tracheal suction performed on a 60 year old man with chronic lymphatic leukaemia, chronic bronchitis, and, possibly, pneumonia. Meningococci of group C:2a were cultured from both specimens; serogrouping and serotyping and subtyping of Neisseria meningitidis were based on conventional methods. ${ }^{12} \mathrm{He}$ was transferred five days later to the intensive care unit with pneumonia.
On day 21 a 71 year old woman with myelomatosis died of septicaemia due to meningococci group C:2a. She had been in the same room as the index case. On day 25 a nurse who had cared for both these patients was admitted to the department of infectious diseases with meningococcal meningitis due to group $\mathrm{C}: 2 \mathrm{a}$. She died four days later of incarceration of the brain despite being treated with benzylpenicillin.

Swabs were taken from the staff and patients in the haematology department, and they were offered vaccination and chemoprophylaxis. For comparison we examined swabs taken from the staff of the infectious diseases and rheumatology departments. All staff who were found to be carriers of meningococci were offered prophylaxis with rifampicin, as were members of their households. These precautions were carried out on days 27 to 29 , and no further cases of meningococcal disease occurred.

Five of the 183 staff in the haematology department were found to be carriers of group $\mathrm{C}$ meningococci (of which four were group C:2a), whereas none of the 247 staff in the departments of infectious diseases and rheumatology were found to be group $\mathrm{C}$ carriers $\left(\mathrm{p}<0 \cdot 05, \chi^{2}\right.$ test) (table). All the C:2a strains among the isolates were resistant to sulphonamide. Swabs that 